\title{
The Storm Tracks Response to Changes in Atmospheric Greenhouse Gas Concentration at the South of Brazil and Southwest Atlantic Ocean
}

\author{
Rose Ane Pereira De Freitas', Fernanda Casagrande'2, Douglas Da Silva Lindemann', \\ Maria Angélica Gonçalves Cardoso ${ }^{3}$, Jeferson Prietsch Machado ${ }^{4}$ \\ ${ }^{1}$ Forecasting and Meteorological Research Center, Federal University of Pelotas (UFPEL), Pelotas, Brazil \\ ${ }^{2}$ Earth System Science Centre (CCST-INPE), National Institute for Space Research (INPE), São José dos Campos, Brazil \\ ${ }^{3}$ Federal University of Santa Maria (UFSM), Santa Maria, Brazil \\ ${ }^{4}$ Oceanography Institute, Federal University of Rio Grande (FURG), Rio Grande, Brazil \\ Email: rosefreitas78@gmail.com, fernanda.casagrande@inpe.br, douglasdasilva.lindemann@gmail.com, \\ magcardoso@gmail.com, jefereson.machado@furg.br
}

How to cite this paper: De Freitas, R.A.P., Casagrande, F., Da Silva Lindemann, D., Cardoso, M.A.G. and Machado, J.P. (2019) The Storm Tracks Response to Changes in Atmospheric Greenhouse Gas Concentration at the South of Brazil and Southwest Atlantic Ocean. Atmospheric and Climate Sciences, 9, 545-557.

https://doi.org/10.4236/acs.2019.94035

Received: May 9, 2019

Accepted: September 7, 2019

Published: September 10, 2019

Copyright () 2019 by author(s) and Scientific Research Publishing Inc. This work is licensed under the Creative Commons Attribution International License (CC BY 4.0).

http://creativecommons.org/licenses/by/4.0/

(c) (7) Open Access

\begin{abstract}
Here we investigate the ocean-atmosphere coupling and the contribution of the Sea Surface Temperature (SST) variations in: 1) Brazil-Malvinas Confluence (BMC) region, 2) Southwest Atlantic Ocean and 3) Southern Brazil. Numerical simulations of the ECHAM5/MPI-OM coupled ocean-atmosphere model were used to analyze the changes in the seasonal trajectory of the extratropical cyclones, in terms of intensification of physical mechanisms and implications for future scenarios. The numerical experiment for the future scenario considered an atmospheric $\mathrm{CO}_{2}$ concentration of approximately 770 $\mathrm{ppm}$, which represents an increment of more than $350 \mathrm{ppm}$ over the current values recorded by the Mauna Loa reference station. For this scenario, the results indicated a Storm Tracks (ST) displacement of $5^{\circ}$ latitude toward south and changes of the meridional transport of sensible heat, close to $50^{\circ} \mathrm{S}$. The increase in SST induces ST intensification and consequently an increase in the occurrence of extratropical cyclones. Overall, in the BMC region, we found a change in the pattern of cyclogenetic activity occurrence, with less frequent, but more intense events. On the Southern Brazilian region, the results of this study indicate increases in rainfall during summer months, whereas, a decrease in frequency and an increase in intensity were found for wintertime. We suggest that these changes could impact the climate dynamic of the Brazilian South coast, with a magnitude yet unknown.
\end{abstract}




\section{Keywords}

Storm Tracks, Confluence Brazil-Malvinas, Atlantic Ocean

\section{Introduction}

Storm Tracks (ST) in the Southern Hemisphere play a key role in both weather and climate, between middle and high latitude through their latitudinal transports, resulting in a significant impact in society, especially in coast regions [1] [2] [3]. By definition, according to [4], ST are defined as regions of maximum variance of geopotencial height in the middle and upper troposphere that arise from disturbances with periods of less than a week. The primary effects of ST mobile in climate include changes in cloudiness, energy balance and sea level. Therefore, they have a significant influence in the atmospheric general circulation [1] [5] [6].

According to [7], the eastern coast of South America is a region that is favorable for the occurrence of cyclogenesis, with a well know seasonal pattern of formation and intensification. The authors suggested that the temperature contrast between the continent and the ocean, associated with the sea surface temperature (SST) gradient of the Brazil-Malvinas Confluence region (BMC), leads to conditions that intensify latent and sensible fluxes; these, in turn, are important for the development of extratropical cyclones.

The SST of the South Atlantic Ocean (SAO) exerts large influence on the climate in South South America, acting as a boundary condition during cyclogenesis events [8]. Meanwhile, the evolution of atmospheric transient systems in the Southwest Atlantic Ocean (SwAO) is directly influenced by the variability of the SST anomaly [9]. Hence, the importance of the study of the variability of extratropical cyclones occurrence in the Brazilian coastal region should be highlighted in regional weather and climate studies, since has a direct influence in Southern of Brazil, changing both air temperature and precipitation patterns [7] [10].

The most well-known cyclone that formed on the ocean and reached the southern region of Brazil was the Catarina Hurricane, which developed over SAO, moving toward the coast (March 2004). [11] described the Catarina system from its genesis (as an extratropical cyclone) until its evolution into Hurricame category. The authors pointed out that for this system the combination of high SST, weak vertical wind shear and strong atmospheric blockage between the middle and high latitudes were the main factors responsible for the genesis.

Climate studies involving the land surface and ocean environment, as Catarina Hurricane case, require a greater detail in the modelling of ocean-atmosphere interactions. The ocean-atmosphere coupling occurs due to interactions at the interface of the oceanic and atmospheric boundary layers, where momentum and energy changes take place [12]. The SST has a relevant role, since it is 
through the SST variations that the energy (sensible and latent heat flux) is exchanged between the atmosphere and the ocean. Therefore, even small SST changes may imply in significant variations in the ocean-atmosphere interface fluxes [13]. In addition, SST may also have significant impacts on the atmospheric circulation and consequently on synoptic systems [14]. In the SwAO region, several studies have characterized the variability and dynamics of the BMC region [2] [15]. However, the knowledge about ocean coastal dynamics and atmospheric processes on the coast of Brazilian south region still lacks conclusive answers, specially for extreme meteorological events [16] [17] [18].

Here we investigate the coupled ocean-atmosphere system using numerical model experiments (short and long-term) and reanalysis. The goal is to assess the ST preferential trajectory, SST anomalies and likely intensification mechanisms as a response to an increase in the Greenhouse Gases concentration (GHC).

\section{Material and Methods}

The BMC, located between $30^{\circ} \mathrm{S}-52.5^{\circ} \mathrm{S}$ and $65^{\circ} \mathrm{W}-40^{\circ} \mathrm{W}$ is one of the most important features of the SwAO basin. BMC is characterized by a significant thermohaline contrast and intense mesoscale activity [13].

For this study, we defined the climatology for two distinct periods: Present Day (PD): from 1980 to 2000 and Future Scenario-Global Warming (GW): from 2080 to 2100 . For PD (GW) the $\mathrm{CO}_{2}$ concentration is approximately $400 \mathrm{ppm}$ (parts per million) $(770 \mathrm{ppm})$. The GW scenario is also used as a measure of climate sensitivity.

The numerical experiment used is the sixth generation of the ECHAM5/MPI-OM model, developed at the Max-Planck Institute of Meteorology (MPI). These simulations are part of the ESSENCE project [19]. The atmospheric component (ECHAM5) presents a 31 levels vertical resolution, spatial resolution of T63 $\left(1875^{\circ}\right)$ in longitude and irregular latitude (96 parallel represented). The ocean component is MPI-OM, with a sea ice model coupled. The vertical ocean profile contains 40 levels, and the first 20 levels are between the surface and $600 \mathrm{~m}$ deep [1] [20].

To validade the PD simulations from ECHAM5/MPI-OM model we compared with reanalysis from ERA-40 [21] and ECHAM5/MPI-OM [20].

\subsection{Storm Tracks (ST)}

Calculations involving the transport of sensible heat, kinetic energy and momentum were used in this work to evaluate the influence of ST on the atmosphere global circulation. The synoptic systems in mid-latitudes are initiated by processes linked to the baroclinic instability, i.e. to the increase in the amplitude of atmospheric disturbances because of the vertical shear of the average wind. This is the conversion of available potential energy from the basic state to the disturbances. Baroclinic instabilities predominate in medium latitudes, acting in the so-called baroclinic zones, where the maximum horizontal temperature gra- 
dients are located and, consequently, where the jets in the high troposphere are located [3] [22]. STs were extracted from daily data at average atmospheric levels $(500 \mathrm{hPa})$ of the ECHAM5/MPI-OM model and were temporarily classified using a high-pass filter to include only systems with growth and decay, at intervals smaller than six days, according to methodology previously described by [23].

\subsection{Sensitive Heat Fluxes at Low Atmospheric Levels}

The sensible heat transport to the north (E1), that is measured around the circle of latitude on the period is calculated using the definitions of the zonal and temporal average, and can be written as follows:

$$
\underbrace{[v T]}_{(1)}=[\underbrace{[\bar{v}]\left[\overline{T^{\prime}}\right]}_{(2)}+\underbrace{\left[\overline{v^{\prime} T^{\prime}}\right]}_{(3)}+\underbrace{\left[\overline{v^{\prime} T^{\prime}}\right]}_{(4)}
$$

where each term of equation represents:

(1) Latitudinal and temporal transport of average sensible heat toward the north.

(2) Contributions of the average southern circulation.

(3) Stationary vortex contributions.

(4) Transient vortex contributions.

It is important to emphasize that the largest contribution to (E1) is given by (4), the transient vortices $\left(v^{\prime} T\right)$.

\subsection{Kinetic Energy}

In order to obtain the ST intensity by using transient wave statistics (E2), the kinetic Energy per unit mass (EKE) from extratropical cyclones trajectories was used seasonally. Thus, an estimation of the ST intensity between the subpolar and subtropical regions is obtained:

$$
\left[\mathrm{EKE}=\frac{1}{2} u^{\prime}+v^{\prime} 2\right]
$$

The first term of the equation is the kinetic energy of the zonal flux, and the second term is the kinetic energy of the southern flow. The bar denotes the mean time.

\section{Results and Discussion}

\subsection{Meridional Transport of Sensible Heat Flux}

The difference between Meridional Transport of sensible heat flux for GW and PD scenario is shown in Figure 1. The potential energy exchanges of the basic state and the potential energy available for the disturbances, indicated by $\left(v^{\prime} T\right)$, were analyzed seasonally for summer (December, January and February, DJF) and winter (June, July and August, JJA). The differences were compared between ECHAM-5/MPI-OM simulations (GW, from 2080 to 2100), and ERA-40 (PD, from 1980 to 2000). 


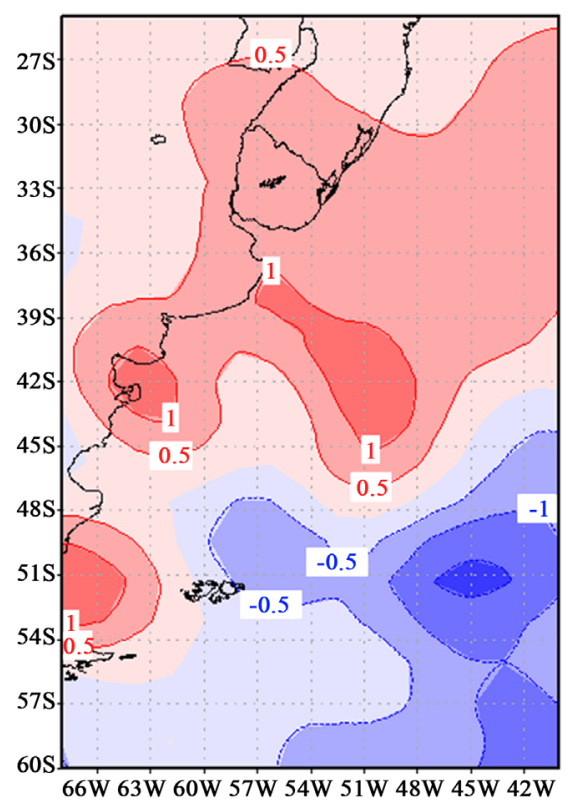

(a)

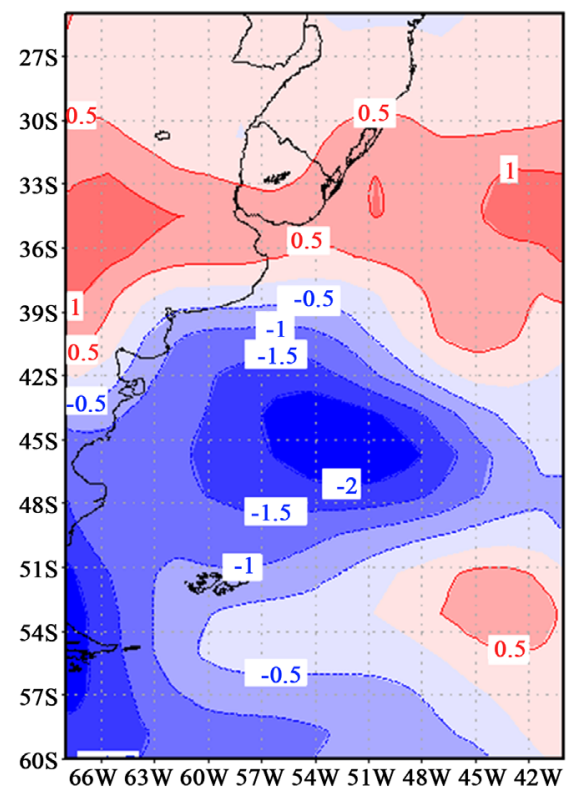

(b)

Figure 1. Difference between Meridional Transport of sensible heat flux for GW and PD scenario $\left(\mathrm{m}^{2} \cdot \mathrm{s}^{-2}\right)$. (a) DJF; (b) JJA.

According to Sato [24], the sensible heat flux is associated with the mechanical transfer of energy by conduction between two regions with different temperatures, and it is greater for warm than for cold regions. Thus, through the results obtained by [7], it is clear that in the BMC region the southern transport of sensitive heat during DJF is distributed in a more limited range latitudinally, suggesting a greater zonal symmetry, evidencing the presence of well-defined cyclogenetic regions on SwAO.

For winter (JJA), the systems activity is distributed over a wide range of latitudes. It is also during JJA that the southern transport of sensible heat reaches the highest values, which may be associated with the higher baroclinidade of the region at high levels during this season, evidenced by the presence of jet streams [3].

Comparing the differences between GW and PD, we draw attention to an intensification of the transports mainly to the polar side of the ST position. The Figure 1(a) shows smooth signal changes on the equatorial side of the ST medium position, emphasizing a transport toward the North, mainly on the BMC region. For JJA (Figure 1(b)) the region presents maximum transport to the South (higher values). Therefore, changes of the meridional transport of sensible heat associated to the increase of the greenhouse gas emissions in GW promoted an acceleration of the basic flow for both seasons (JJA and DJF).

The ST observed displacement for south is approximately $5^{\circ}$ latitudes as previously observed by Freitas et al. (2018), meridionally distributed on a regular form. Hence, inducing a smaller (larger) cyclonic activity close from $50^{\circ} \mathrm{S}\left(60^{\circ} \mathrm{S}\right)$. Thus, we suggest that in the GW conditions, the ST activity remain persistent 
during all year and the heat transport toward south can reach the maximum values during JJA. For DJF the BMC region may have the sensible heat transport changed toward north.

According to [25], the ST displacement to the south and decrease in cyclogenetic activity observed during the DJF may have a relation with the reduction and displacement of the maximum baroclinic region toward the pole. The reason for this behavior is due to changes that can occur in meridional sensible heat gradient throughout the warm troposphere.

The $\mathrm{BMC}$ region is important due to presence of ocean fronts, responsible for intermediate water mass formation in the Atlantic Ocean as a whole [26] [27]. Assessing the redistribution of extratropical cyclones over the mid-latitudes region for the GW scenario, we found that transport becomes more intense toward north during DJF in the BMC. For JJA months, the maximum values occur toward south.

The intensification of the sensible heat flux in the BMC region is directly associated to the ST position changes. For the future scenario, the numerical experiment in BMC showed increases in the basic flow for both DJF and JJA. Following our results we suggest that, in a future scenario with larger than present GHG concentrations, larger cyclone activity in latitudes around $60^{\circ} \mathrm{S}$ are to be expected, while in mid-latitudes (approximately $50^{\circ} \mathrm{S}$ ) less frequent cyclogenetic activity is to be observed, however more intense, than what is observed for the present scenario.

\subsection{Kinetic Energy (KE)}

The Kinetic Energy (KE) balance allows a better understanding of the energetic processes related to the mechanisms of growth and decay of atmospheric disturbances at different scales. The differences of KE between GW and PD are shown in Figure 2(a) and Figure 2(b). Negative values are found in the north of the $45^{\circ} \mathrm{S}\left(40^{\circ} \mathrm{S}\right)$ for DJF (JJA). Still, positive values concentrate between $45^{\circ} \mathrm{S}$ and $62^{\circ} \mathrm{S}\left(47^{\circ} \mathrm{S}\right.$ and $\left.60^{\circ} \mathrm{S}\right)$ during DJF (JJA). The highest values of KE are found mainly in the Malvinas Islands region and are related to an increase in the activity of extratropical cyclones as well as to an intensification in the direction of the westward flux, also being conditioned to the seasonal variation of the Antarctic sea ice in the months of DJF and JJA. The results indicate that under GW conditions, more intense systems will likely act in these regions during JJA (Figure 2(b)). These regions of mid and high latitudes can become sources of more intense cyclogenesis, but will present a displacement Southwards when compared to $\mathrm{PD}$.

Higher values of KE found during DJF under GW conditions (not shown) demonstrate that during this period of the year the BMC region may present larger baroclinic activity, consequently inducing changes in climate features of the south coast of South America during DJF. On the other hand, during JJA, there is a possibility of decreasing in KE magnitude, demonstrating that less systems will act in the BMC region. 


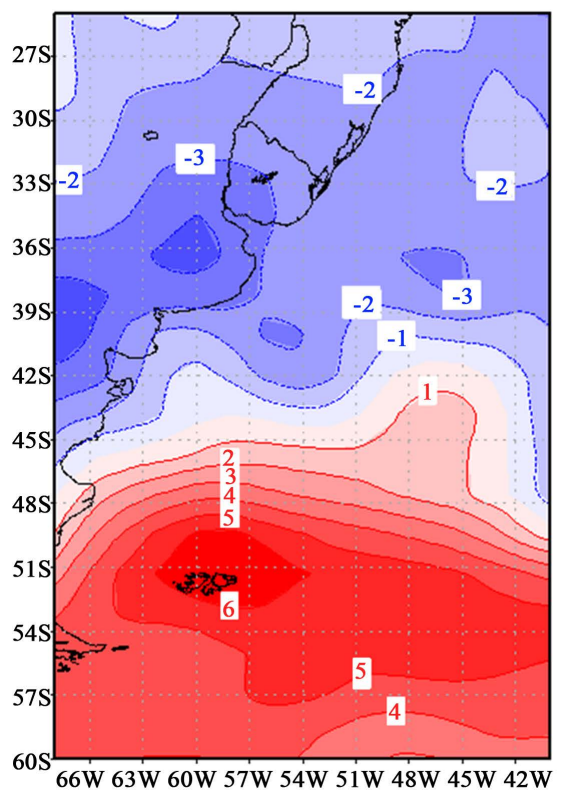

(a)

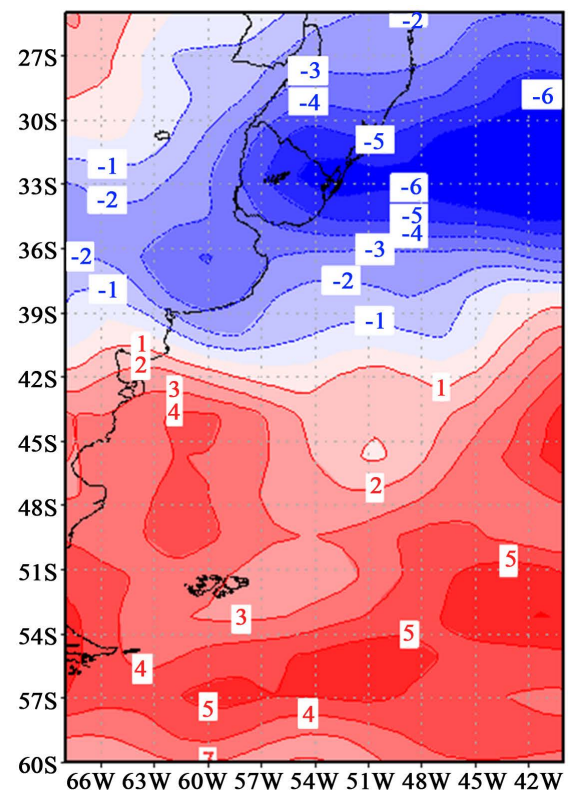

(b)

Figure 2. Difference between Kinetic Energy $\left(\mathrm{m}^{2} \cdot \mathrm{s}^{-2}\right)$. for PD and GW scenario. (a) DJF; (b) JJA.

\subsection{Transport of Momentum}

The differences between GW and PD of the horizontal momentum transports $\left(u^{\prime} v^{\prime}\right)$ are presented in Figure 3(a) and Figure 3(b). This transport represents the changes between KE of the disturbances and KE of the basic state.

For the PD and GW climatology, there is intense zonal symmetry of the horizontal transport of momentum during DJF, where the vortices are confined to a narrow range of latitudes, indicating that the horizontal transport of momentum presents less spatial variability during DJF (because systems evolve and are kept within the jet). For the JJA period, the activity of these meteorological systems extends through a greater range of latitudes, also presenting an interruption of the flux over South America, possibly caused by the orography of the region [28] [29].

The differences for the horizontal transport of momentum, presented in Figure 3, indicate that the mainly differences during DJF (Figure 3(a)) are found on the East of South America, particularly around $55^{\circ} \mathrm{S}$. For JJA (Figure 3(b)) the highest values are centered on OAS, varying between $45^{\circ} \mathrm{S}$ and $65^{\circ} \mathrm{S}$ latitudes. The largest values of the anomalies presented above are found in a region of connection between the Antarctic and Southern Ocean, which is associated with the largest southern thermal gradient.

Comparing PD and GW scenario, the horizontal transport of momentum is intensified and increases the area of maximum activity of the polar side of the ST in the middle latitudes. During JJA (Figure 3(b)) the region of maximum activity is located around $50^{\circ} \mathrm{S}$, thus the horizontal transport of momentum remains more intense, contributing to the acceleration of the basic flow, while its greater zonal symmetry continues to occur during DJF (Figure 3(a)). 


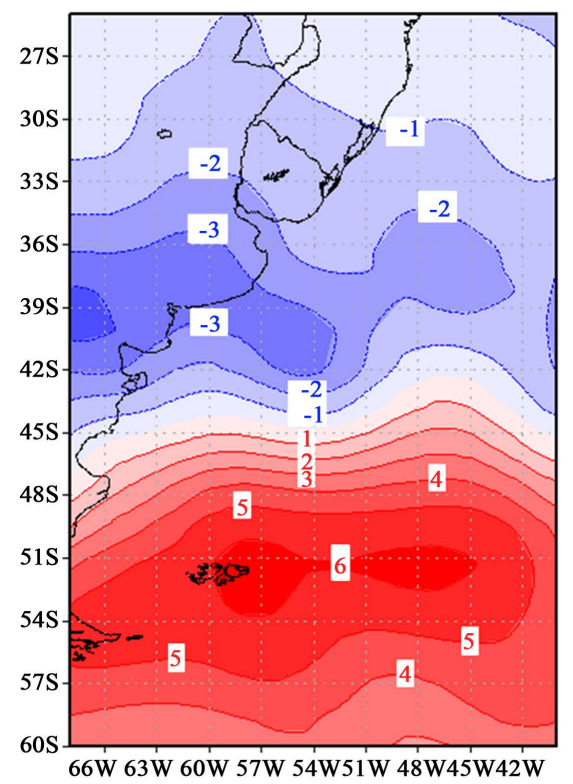

(a)

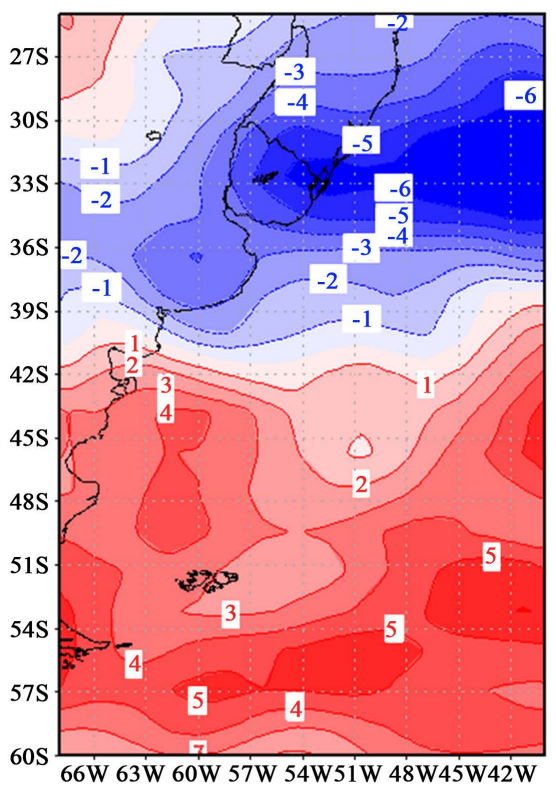

(b)

Figure 3. Difference between horizontal transport of momentum $\left(\mathrm{m}^{2} \cdot \mathrm{s}^{-2}\right)$. For PD and GW scenario. (a) DJF; (b) JJA.

\subsection{Sea Surface Temperature (SST)}

According to [1], SST in mid-latitudes is fundamental for the asymmetric distribution and ST intensification of the lower troposphere. In addition, the region area is characterized by a strong southern gradient, but, under GW conditions, the gradient is even more pronounced. These differences in SST are even more evident when comparing SST between PD and GW (Figure 4(a) and Figure 4(b)), it can be seen that SST shows a tendency to increase in all SAO to GW, becoming even more evident during JJA (Figure 4(b)). The greatest differences are observed following the Malvinas and Brazil Currents, with the highest values on the Malvinas Current.

We suggest that the SST strong increase in middle latitudes is determinant for asymmetry and intensification of ST, associated by the heat flux in GW conditions. Therefore, it can be assumed that when the atmosphere is exposed to high $\mathrm{CO}_{2}$ concentrations, the associated SST gradient will be higher.

Thus, the changes in ST are likely to be related to changes in SST patterns, and might lead to faster development of eddies and differences in the asymmetric distribution of ST. Besides, the projections of climate change made in GW scenario should lead to a series of changes that may modify the general circulation of the atmosphere [30].

\subsection{Sea Ice}

Sea ice is a key component of the climate system due to its role in radiative processes, mass exchange and momentum. According to [31], sea ice modulates ocean-atmosphere interaction in Antarctic region. The sea ice variability in Austral Ocean occurs at different time scales, having a significant impact in 


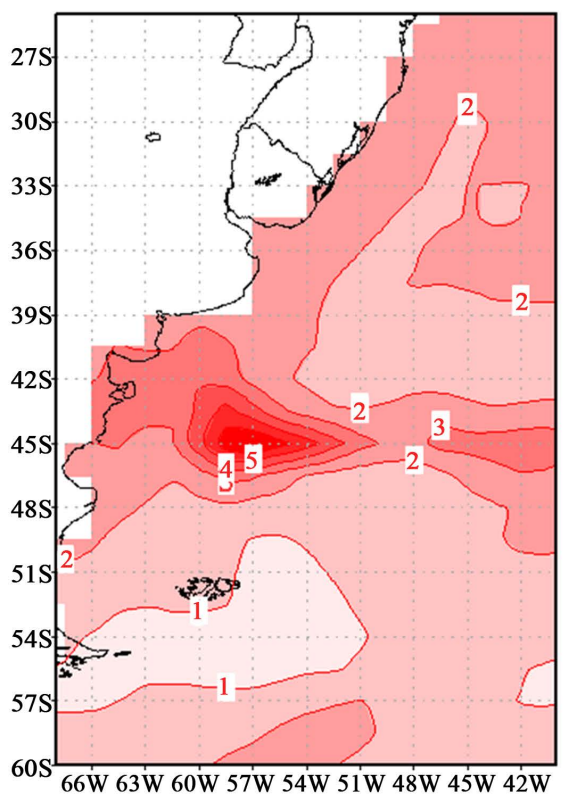

(a)

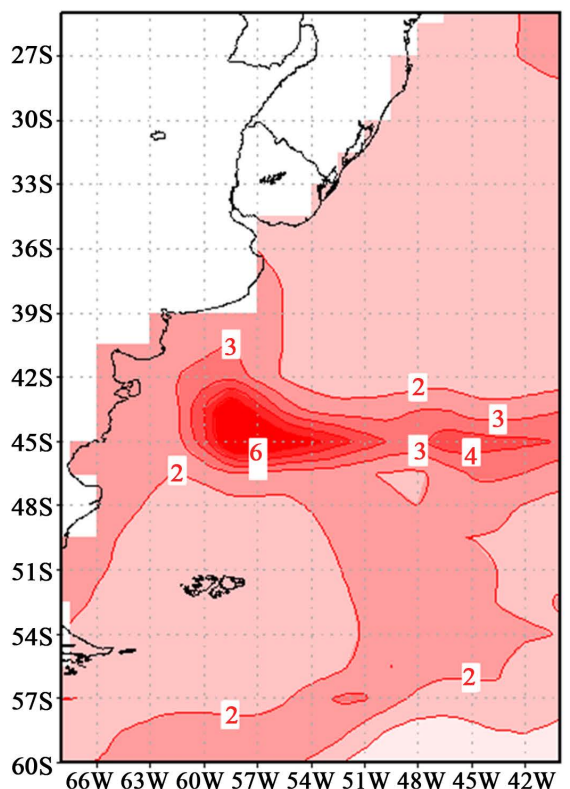

(b)

Figure 4. Difference between SST $\left({ }^{\circ} \mathrm{C}\right)$ for PD and GW scenario. (a) DJF; (b) JJA.

processes involving deep water and and changes of the water bodies, more precisely in the Weddell Sea [32]. Thus, it is very important to evaluate the changes in sea ice thickness around Antarctic region and its association with ST.

For PD conditions the sea ice thickness annual average reaches a maximum of 3.5 meters in the Weddell Sea and Antarctic Peninsula [33]. Figure 5 shows a shrinkage of approximately $5^{\circ}$ in the entire extent and thickness of sea ice, mainly in the Antarctic Peninsula and Weddell Sea. The differences shown clearly demonstrate a decrease in sea ice thickness up to 2.5 meters to north of the Antarctic Peninsula during DJF (Figure 5(a)) and up to 2.0 meters in JJA (Figure 5(b)). For the Weddell Sea region, the reduction is close to $1.0(0.7)$ meter in DJF (JJA).

The differences shown in Figure 5 demonstrate an important point for the ST displacement to the South direction, which is the shrinkage in GW scenario from the heating influenced by the increase in $\mathrm{CO}_{2}$ concentration. Also, it is noted that this decrease in sea ice may be of great relevance in the zonal baroclinicity, influenced by the thermal contrast between sea ice and ocean, agreeing with the results obtained by [34], who evaluated the interannual variations of GM around Antarctica for the period from 1979 to 2000, and its possible impacts on ST. The results obtained by [34] showed that sea ice has a very well established seasonal cycle and a significant annual variation, with anomalies in the sea ice extent showing a good agreement with the anomalous positioning of ST.

Thus, the displacement around $5^{\circ}$ toward the South of the ST (Figure 1 and Figure 2), under GW conditions also can be attributed to anomalies in the sea ice extension. In this way, it can be assumed that a significant zonal baroclinic influence occurs due to the thermal contrast between sea ice and ocean. 


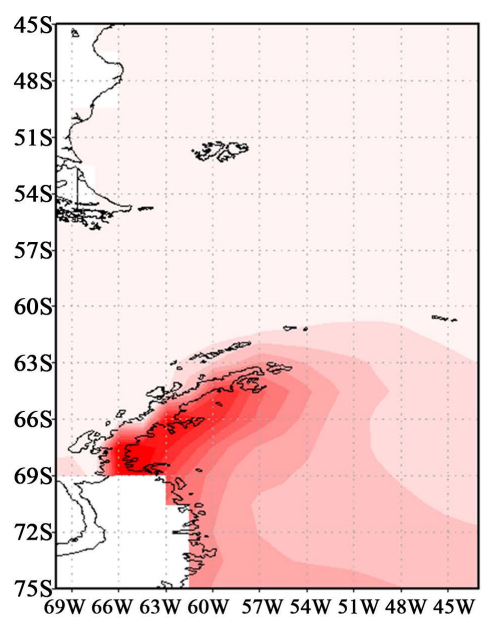

(a)

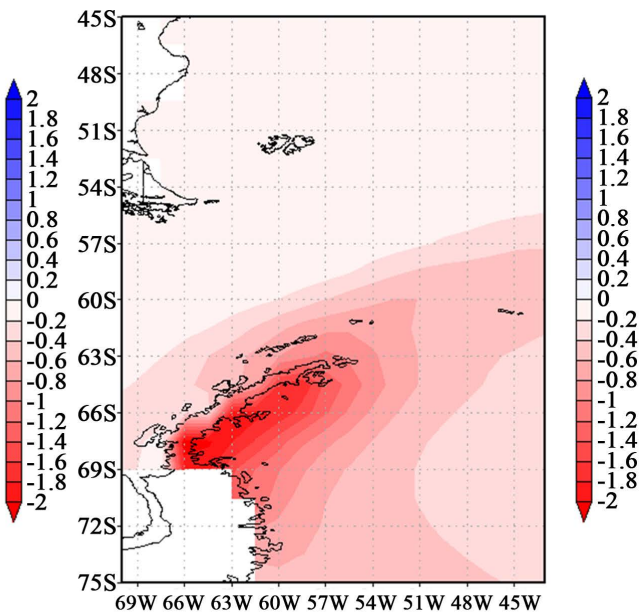

(b)

Figure 5. Difference between Sea Ice (meters) for PD and GW scenario. (a) DJF; (b) JJA.

\section{Conclusions}

Reduction in KE values in GW scenario takes place during DJF, which may affect the climatic conditions of the south coast of South America. For JJA, we also found a decrease in KE magnitude associated with a decrease in synoptic systems (BMC region) due to displacement of ST to South. Higher values of KE indicate that the regions between $45^{\circ} \mathrm{S}$ and $60^{\circ} \mathrm{S}$ should become regions of greater baroclinic activity in both JJA and DJF. JJA was the season with the highest number of active extratropical cyclones. The trend will be that during JJA, under GW conditions, more intense systems will follow the trajectory in the region in a scenario that tends to present severe storms.

The turbulent kinetic energy associated with ST displacement shows an increase in SAO activity as well as an intensification toward the West flow. This suggests that, in a future scenario, the average atmospheric flow interacts with ST mainly during JJA. Still on the BMC region, it can be noticed that the intensification of the sensible heat flux is liekly to be directly associated to the variation in the ST position. Probably, under GW conditions, less cyclogenetic activity is expected, but more intense than the current scenario indicates. The region may have an acceleration in the basic flow for both JJA and DJF, and this change in the southern transport of sensible heat is also associated with the increase in $\mathrm{CO}_{2}$ emission.

We observed that the SAO presents intensification of the southern transport of sensible heat in a latitudinal range around $50^{\circ} \mathrm{S}$ under GW conditions. A high SST can contribute to the intensification of ST, inducing the increase of occurrence of extratropical cyclones in SwAO. It is important to note that during JJA the sensible heat flux is more intense than in DJF (Figure 2). The limitations found in the study are related to the data used for reanalyses and to the use of a global climate model that should be considered in the climatic studies in high latitudes of the Southern Hemisphere due to the lack of observational data. Regarding the use of climate models, it is acknowledged that global (and even re- 
gional) climate models have deficiencies in the coupling between ocean and atmosphere, so the more qualitative evaluation of ST represented by models needs to be carefully investigated, since factors such as the model resolution is in many cases presented as the main cause of underestimates of ST.

\section{Conflicts of Interest}

The authors declare no conflicts of interest regarding the publication of this paper.

\section{References}

[1] Bengtsson, L., Hodges, K.I. and Roeckner, E. (2006) Storm Tracks and Climate Change. Journal of Climate, 19, 3518-3543. https://doi.org/10.1175/JCLI3815.1

[2] Rocha, R.P., Sugahara, S. and Silveira, R.B. (2004) Sea Waves Generated by Extratropical Cyclones in the South Atlantic Ocean: Hind-Cast and Validation against Altimeter Data. Weather and Forecasting, 19, 398-410. https://doi.org/10.1175/1520-0434(2004)019<0398:SWGBEC>2.0.CO;2

[3] Hoskins, B.J. and Hodges, K.I. (2005) A New Perspective on Southern Hemisphere Storm Tracks. Journal of Climate, 18, 4108-4129.

https://doi.org/10.1175/JCLI3570.1

[4] Trenberth, K.E. (1991) Storm Tracks in the Southern Hemisphere. Journal of the Atmospheric Sciences, 48, 2159-2178. https://doi.org/10.1175/1520-0469(1991)048<2159:STITSH $>2.0 . C O ; 2$

[5] Lau, N.-C. (1988) Variability of the Observed Midlatitude Storm Tracks in Relation to Low-Frequency Changes in the Circulation Pattern. Journal of the Atmospheric Sciences, 45, 2718-2743. https://doi.org/10.1175/1520-0469(1988)045<2718:VOTOMS>2.0.CO;2

[6] Ting, M. and Held, I.M. (1990) The Stationary Wave Response to a Tropical SST Anomaly in an Idealized GCM. Journal of the Atmospheric Sciences, 47, 2546-2566. https://doi.org/10.1175/1520-0469(1990)047<2546:TSWRTA>2.0.CO;2

[7] Gan, M.A. and Rao, B.V. (1991) Surface Cyclogenesis over South America. Monthly Weather Review, 119, 1293-1302. https://doi.org/10.1175/1520-0493(1991)119<1293:SCOSA >2.0.CO;2

[8] Diaz, A.F., Studzinski, C.A. and Mechoso, C.R. (1998) Relationships between Precipitation Anomalies in Uruguay and Southern Brazil and Sea Surface Temperature in the Pacific and Atlantic Oceans. Journal of Climate, 11, 251-271. https://doi.org/10.1175/1520-0442(1998)011<0251:RBPAIU>2.0.CO;2

[9] Pezzi, L.P. and Souza, R.B. (2009) O uso da temperatura da superfície do mar emestudosclimáticos. In: Souza, R.B., Ed., Oceanografia por satélites, Oficina de Textos, São Paulo, 117-133.

[10] Seluchi, M. and Saulo, A.C. (1998) Possible Mechanisms Yielding an Explosive Coastal Cyclogenesis over South America: Experiments Using a Limited Area Model. Australian Meteorological Magazine, 47, 309-320.

[11] Pezza, A.B. and Simmonds, I. (2005) The First South Atlantic Hurricane: Unprecedented Blocking, Low Shear and Climate Change. Geophysical Research Letters, 32, L15712. https://doi.org/10.1029/2005GL023390

[12] Pezzi, L.P., Souza, R.B., Acevedo, O., Wainer, I., Mata, M.M., Garci, C.A.E. and De Camargo, R. (2009) Multiyear Measurements of the Oceanic and Atmospheric Boun- 
dary Layers at the Brazil-Malvinas Confluence Region. Journal of Geophysical Research, 114, D19103. https://doi.org/10.1029/2008JD011379

[13] Pezzi, L.P., Souza, R.B. and Quadro, M.F.L. (2016) Uma Revisão dos Processos de Interação Oceano-Atmosfera em Regiões de Intenso Gradiente Termal do Oceano Atlântico Sul Baseadaem Dados Observacionais. Revista Brasileira de Meteorologia, 31, 428-453. https://doi.org/10.1590/0102-778631231420150032

[14] Silva, W.L., Nascimento, M.X. and Menezes, W.F. (2015) Atmospheric Blocking in the South Atlantic during the Summer 2014: A Synoptic Analysis of the Phenomenon. Atmospheric and Climate Sciences, 5, 386-393. https://doi.org/10.4236/acs.2015.54030

[15] Silveira, I.C.A., Calado, L., Castro, B.M., Cirano, M., Lima, J.A.M. and Mascarenhas, A.D.S. (2004) On the Baroclinic Structure of the Brazil Current Intermediate Western Boundary Current System at $22^{\circ}-23^{\circ} \mathrm{S}$. Geophysical Research Letters, 31, L14308. https://doi.org/10.1029/2004GL020036

[16] Cataldi, M., Assad, L.P.F., Torres Jr., A.R. and Alves, J.L.D. (2010) Estudo da influência das anomalias da TSM do Atlântico Sul extratropical naregião da Confluência Brasil Malvinas no regime hidrometeorológico de verão do Sul e Sudeste do Brasil. Revista Brasileira de Meteorologia, 25, 513-524. https://doi.org/10.1590/S0102-77862010000400010

[17] Souza, R.B. and Robson, I.S. (2004) Lagrangian and Satellite Observations of the Brazilian Coastal Current. Continental Shelf Research, 24, 241-262.

[18] Chiessi, C.M., Mulitza, S., Groeneveld, J., Silva, J., Campos, M.C. and Gurgel, M.H.C. (2014) Variability of the Brazil Current during the Late Holocene. Palaeogeography, Palaeoclimatology, Palaeoecology, 415, 28-36. https://doi.org/10.1016/j.palaeo.2013.12.005

[19] Sterl, A., et al. (2008) When Can We Expect Extremely High Surface Temperatures? Geophysical Research Letters, 35, L14703. https://doi.org/10.1029/2008GL034071

[20] Jungclaus, J.H., Keenlyside, N., Botzet, M., Haak, H., Luo, J.-J., Latif, M., Marotzke, J., Mikolajewicz, U. and Roeckner, E. (2006) Ocean Circulation and Tropical Variability in the Coupled Model ECHAM5/MPI-OM. Journal of Climate, 19, 3952-3972. https://doi.org/10.1175/JCLI3827.1

[21] Uppala, S.M., et al. (2006) The ERA-40 Re-Analysis. Quarterly Journal of the Royal Meteorological Society, 131, 2961-3012.

[22] Reboita, M.S., Gan, M.A., Rocha, R.P. and Custódio, I.S. (2017) Ciclones em Superfícienas Latitudes Austrais: Parte I-Revisão Bibliográfica. Revista Brasileira de Meteorologia, 32, 171-186. https://doi.org/10.1590/0102-77863220010

[23] Freitas, R.A., Lindemann, D., Justino, F. and Machado, J. (2018) Influência do Aquecimento Global nas Trajetórias e Intensidades dos Ciclones Extratropicais no Hemisfério Sul. Anuário do Instituto de Geociências, 41, 297-304. https://doi.org/10.11137/2018_2_297_304

[24] Sato, O.T. (2009) Fluxo de calor oceanico medido por satélites. In: Souza, R.B., Ed., Oceanografia por Satélites, Oficina de Textos, São Paulo, 165-184.

[25] Yin, J.H. (2005) A Consistent Poleward Shift of the Storm Tracks in Simulations of 21st Century Climate. Geophysical Research Letters, 32, L18701. https://doi.org/10.1029/2005GL023684

[26] Peterson, R.G. and Stramma, L. (1991) Upper-Level Circulation in the South Atlantic Ocean. Progress in Oceanography, 26, 1-73. https://doi.org/10.1016/0079-6611(91)90006-8

[27] Acevedo, O.C., Pezzi, L.P., Souza, R.B., Anabor, V. and Degrazia, G.A. (2010) At- 
mospheric Boundary Layer Adjustment to the Synoptic Cycle at the Brazil-Malvinas Confluence, South Atlantic Ocean. Journal of Geophysical Research, 115, D22107. https://doi.org/10.1029/2009JD013785

[28] Sinclair, M.R. (1995) A Climatology of Cyclogenesis for the Southern Hemisphere. Monthly Weather Review, 123, 1601-1619. https://doi.org/10.1175/1520-0493(1995)123<1601:ACOCFT>2.0.CO;2

[29] Simmonds, I. and Keay, K. 2000. Mean Southern Hemisphere Extratropical Cyclone Behavior in the 40-Year NCEP-NCAR Reanalysis. Journal of Climate, 13, 873-885. https://doi.org/10.1175/1520-0442(2000)013<0873:MSHECB >2.0.CO;2

[30] Vera, C., Silvestri G., Liebman, B. and González, P. (2006) Climate Change Scenarios for Seasonal Precipitation in South America from IPCC AR4 Models. Geophysical Research Letters, 33, L13707. https://doi.org/10.1029/2006GL025759

[31] Justino, F. and Peltier, R. (2006) Influence of Present Day and Glacial Surface Conditions on the Antarctic Oscillation/Southern Annular Mode. Geophysical Research Letters, 33, L22702. https://doi.org/10.1029/2006GL027001

[32] Comiso, J.C. and Gordon, A.L. (1998) Interannual Variability in Summer Sea Ice Minimum, Coastal Polynyas, and Bottom Water Formation in the Weddell Sea. In: Jeffries, M., Ed., Antarctic Sea Ice: Physical Processes, Interactions, and Variability. Antarctic Research Series, Volume 74, American Geophysical Union, Washington DC, 293-315. https://doi.org/10.1029/AR074p0293

[33] Parkinson, C.L. and Cavalieri, D.J. (2012) Antarctic Sea Ice Variability and Trends, 1979-2010. The Cryosphere, 6, 871-880. https://doi.org/10.5194/tc-6-871-2012

[34] Pezza, A.B. and Ambrizzi, T. (2003) Variability of Southern Hemisphere Cyclone and Anticyclone Behavior: Further Analysis. Journal of Climate, 16, 1075-1083. https://doi.org/10.1175/1520-0442(2003)016<1075:VOSHCA $>2.0$. CO;2 